\title{
Direito Penal da Loucura: Medida de Segurança e Reforma Psiquiátrica
}

\author{
CRIMINAL LAW OF MADNESS: MEASURE OF SECURITY \\ AND THE PSYCHIATRIC REFORMATION
}

Paulo Vasconcelos Jacobina ${ }^{(*)}$

\section{RESUMO}

O autor situa a loucura dentro do Sistema Penal Brasileiro, questionando a eficácia da aplicação da medida de segurança na recuperação do doente mental que venha a praticar crime. Destaca as contradições entre a Lei de Reforma Psiquiátrica - que busca a humanização do tratamento de paciente com transtornos mentais - e a Lei de Execuções Penais, demonstrando o caráter punitivo da medida de segurança - embora não seja reconhecida como sanção penal - já que se submete ao Sistema Penitenciário ao invés do Sistema Único de Saúde. Apresenta uma crítica ao modelo de recuperação adotado, onde ocorre uma verdadeira inversão de papéis, em que o julgador assume o papel de clínico, ordenando a internação e alta, como medida que parece visar mais a proteção da sociedade do que a reabilitação e reintegração do enfermo ao corpo social, devolvendo-Ihe a cidadania e a dignidade.

\section{Descritores}

Transtornos mentais; Direito penal; Psiquiatria legal; Reabilitação; Instituições de saúde; Reforma psiquiátrica.

\section{ABSTRACT}

The author situates mental disorders inside Brazilian Health System, questioning the efficacy of the application of 'medidas de segurança' to the

(*) Procurador Regional da República, Especialista em Direito Sanitário e Mestre em Direito Econômico. E-mail: jacobina@prse.mpf.gov.br. Entrada: 17.7.2003 _ Aprovado 22.9.2003. 
recovery of the mentally ill that come to practice a crime. He stands the contradictions amidst the law regarding "Psychiatric Reform" - that looks to humanize the handling of patients with mental disorders - and the law regarding "Criminal Executions", demonstrating the punitive character of 'medidas de segurança' - in spite of not being recognized as criminal punishment - inasmuch as it abides to the Criminal System and not to SUS. He criticizes the adopted model of recovery, where there is a inversion of papers, the judge acting as physician, ordering internments and dismissals, looking as social protection more than rehabilitation and reintegration of the mentally ill into social body, giving him back his citizenship and dignity.

\section{Keywords}

Mental disorders; criminal law; forensic psychiatry; rehabilitation; health facility environment

Pode-se estabelecer, com um estudo mais profundo, que a legislação penal e processual penal traz uma concepção da loucura, e uma forma de lidar com ela. A legislação sanitária também está imbuída de uma determinada concepção ideológica de loucura, e de uma forma de lidar com ela. Assim, é necessário fazer uma breve retrospectiva histórica e filosófica da loucura, para ficar evidente que essas concepções e modos de lidar não são nem os únicos, nem os últimos, nem os melhores, mas apenas projeções dos contextos ideológicos nos quais foram produzidos. Vale dizer: municiando o jurista de um saber crítico sobre a loucura, da contextualização desse saber e das formas com as quais as sociedades têm lidado com ela, pode-se eventualmente obter uma maior facilidade no manuseio da legislação, na sua interpretação e aplicação - adequando-a, ademais, aos grandes princípios humanistas insertos na Constituição, mas nem sempre levados em conta quando da gestão jurídica da insanidade, realizada na prática pelos operadores do direito.

O conceito de loucura não é unívoco. Não se pode admitir que existe um conceito de loucura vagando pelo mundo platônico das idéias, paulatinamente desvendado pelo progresso da ciência. A loucura sempre foi, em todas as sociedades, uma questão de como a pessoa se relaciona consigo mesma, como se relaciona com os outros e, principalmente, como vê o mundo e como é vista por este. Alguém pode ser considerado louco num determinado contexto, e ser um líder, ou um xamã, em outro.

$\mathrm{Na}$ verdade, prevalece ainda no Direito uma noção desumanizadora da loucura, fruto do desenvolvimento do racionalismo e do positivismo tão arraigados nas ciências desde a sua origem. Nessa desumanização, a loucura passa a ser uma entidade, equipara-se à doença. Ela passa a ter uma vontade, que supera a própria vontade humana e deslegitima o tão discutido princípio filosófico do livre-arbítrio, colocando-se além da 
punição. Mas não além do julgamento e da exclusão. Embora reputando irresponsável e inimputável o louco, porque tomado por uma entidade não-humana com uma vontade superior à sua, o direito brasileiro contemporâneo prorroga a jurisdição da justiça criminal para que a doença possa sofrer um julgamento penal e ser punida - sendo esse o significado do instituto da medida de segurança. Um instituto que pune a loucura, sob o fundamento nem sempre explícito de a desmascarar, arrancá-la do ser humano. $E$ que, se de resto acaba restringindo a liberdade do portador da doença, por via de um internamento que, se no discurso é não punitivo, na prática lhe arranca a liberdade e a voz. Tal se dá porque ali onde um desavisado vê uma pessoa privada de liberdade por força de uma medida de segurança, o direito vê diferente - a loucura seria algo não-humano, e a pessoa portadora na loucura seria um esvaziado hospedeiro, cuja vontade (ou essência) foi sobrepujada. "Na situação extrema o louco não age, mas sim é agido. Quem fala com sua voz, quem anda com suas pernas, quem olha com seus olhos não é ele: é a doença", afirma Fuhrer ${ }^{(1)}$, imbuído de tal ideologia ao estudar a medida de segurança. Nesse sentido, a medida de segurança, mais do que uma defesa social, seria uma paradoxal defesa da pessoa portadora de doença mental contra a sua própria loucura. Ou seja, o objetivo declarado dela seria salvar o louco de sua desumana insensatez, o que não deixa de ser paradoxal.

\section{LEMBRANDO DA HISTÓRIA}

Essa construção lenta de uma base ética para a loucura possibilitou o advento da psiquiatria com as bases complexas que tem hoje e iniciou um diálogo, em bases nem sempre amistosas entre os juristas e os médicos, um diálogo de retroalimentação e disputa de competências que veio a se refletir na forma ambígua com que a loucura é tratada ainda hoje no direito positivo, e mais - veio a solapar as bases clássicas do direito penal e do próprio direito social de punir, ao tempo em que pôs em xeque as noções de liberdade e de livre-arbítrio, criando reflexos que estão na raiz da própria concepção contemporânea de responsabilidade penal.

Rememorando essa história, encontramos Pinel no seu gesto mítico de soltar os loucos - gesto no qual a moderna psiquiatria enxerga a fundação da sua própria história, a história da perfeita equiparação entre loucura e doença mental. Estabeleceram-se, a um só tempo, dois dos pilares do que gostamos de enxergar como tratamento "científico" ao louco - a medicalização do manicômio e o estudo sistemático, com pressupostos científicos, sobre essa nova categoria nosológica e suas formas de tratamento.

Explicitam-se, nesse passo, outros pressupostos que lastreiam a concepção contemporânea de loucura, notadamente no direito penal - a lou-

(1) FÜHRER, Maximiliano Roberto Ernesto. "Tratado da inimputabilidade no direito penal". São Paulo: Malheiros Ed., 2000, p. 132. 
cura como "inferioridade moral", estado do qual as pessoas poderiam ser "trazidas de volta" ao rumo da "sanidade" se afastadas das forças alienadoras da sociedade - vale dizer, se perdessem a liberdade psicológica da loucura, e fossem guiados pela mão segura do alienista, não lhes restaria mais do que trilhar o caminho da normalidade. A cura, nessa concepção, seria o retorno a um estado ideal simbolizado pelo homo medius - o estado "normal" - por mais metafísica que a noção de normalidade possa parecer.

Dentre os que esquadrinharam a mente humana, os historiadores apontam a noção de monomania trazida por Esquirol: um sujeito com monomania caracterizar-se-ia por permanecer razoável em todos os pontos, menos naquele que diz respeito ao crime que cometeu - onde se mostra como louco. Essa loucura pode aparecer num átimo, mesmo estando insuspeita por todos que convivem com ele, e sumir após o cometimento do desatino. Essa alteridade que domina o sujeito no momento do seu ato irrazoável deixá-lo-ia irresponsável pelo crime.

A maior conseqüência - dentre tantas conseqüências relevantes que o conceito de monomania trouxe para o desenvolvimento da psiquiatria e das relações desta com o direito foi exatamente aquela de não ser mais necessário o rompimento total com a razão para que se pudesse vislumbrar a loucura - ela poderia estar oculta ali mesmo onde estava invisível ao não-médico. Além disso, como no caso da loucura moral, ela pode estar além do processo de cura psiquiátrica - como aplicar um tratamento de fundo moral exatamente em quem está incapacitado para esse aspecto da vida humana?

Isso teria, também, a conseqüência de trazer insegurança jurídica, na medida em que, se o fundamento da sanção penal é o livre-arbítrio e o fundamento da internação hospitalar é o tratamento, os loucos morais estão numa zona de ninguém - não podem ser tratados - por questões técnicas, já que dificilmente seriam curáveis. Não podem ser presos, por questões jurídicas - são irresponsáveis pelos seus atos. A criminologia teria que buscar um outro fundamento para retirar-Ihes a liberdade. Esse fundamento é a periculosidade, expressa como a necessidade de defesa social. Mais tarde, a criminologia irá negar o próprio livre-arbítrio, e considerar de forma determinística praticamente toda a esfera de ação humana, indiferenciando, no limite, os loucos dos criminosos $^{(2)}$.

A idéia de degeneração é de uso corrente na medicina, para designar uma mudança que implica menor funcionalidade. No âmbito psiquiátrico, porém, foi usada por Morel de forma um tanto mais específica. Ele parte de uma concepção ideal de homem - um adão hipotético, pré-queda, um homem em que o físico está absolutamente submisso ao moral - vale dizer, um homem mítico, completamente responsável, completamente racional, plenamente capaz de controlar totalmente a si mesmo, plenamente conhecedor de si mesmo. A partir da queda, do pecado original, a espécie

(2) LOMBROSO, apud CARRARA, Sérgio. "Crime e loucura: o aparecimento do manicômio judiciário na passagem do século". São Paulo: Ed. Edusp, 1998. p. 62. 
humana entra num caminho de decadência, que irá resultar na queda total, na total degeneração, enfim - tão mais decadente quanto mais, ao longo da história, a espécie humana se afasta dessa origem divina.

Assim, nesse antidarwinismo, os degenerados seriam uma forma de "visão antecipada" da decadência que nos aguarda a todos num futuro remoto, um desvio patológico que antecipa a queda final da espécie humana. Apesar de seus pressupostos antievolucionistas, alguns postulados lamarckianos eram aceitos pela teoria da degeneração, em especial o postulado da hereditariedade dos caracteres adquiridos.

A idéia de degeneração estaria na base da própria idéia de doença mental - embora ele enxergasse "doenças mentais não-degenerativas", e portanto curáveis; mesmo estas poderiam encaminhar à degeneração os doentes e seus descendentes. Assim, a angústia dos psiquiatras consistente no fato de nunca terem achado lesões biológicas nas autópsias que se faziam nos loucos, ao menos lesões que fossem diversas daquelas encontráveis nos ditos normais - pôde ser substituída por uma hipótese de má conformação de um sistema nervoso degenerado. Essa mesma má conformação evidenciava-se pela irracionalidade da conduta.

Eis a psiquiatria estendendo seu domínio a praticamente todo o campo penal. Não há mais crime que não seja, em alguma monta, uma evidência de degeneração. Não há mais criminoso que não seja, de algum modo, um paciente psiquiátrico potencial. Não há, portanto, mais nenhum processo penal que não seja, potencial e prejudicialmente, passivel de submissão a incidente de insanidade mental. A sanidade passou a ser uma presunção juris tantum, e das mais frágeis.

Para Charcot - que iria mais tarde influenciar o próprio Freud - a suscetibilidade à hipnose seria reveladora de sintomas de histeria, percebidos ou desapercebidos. Em seus polêmicos estudos sobre a histeria, ele fazia exibições quase teatrais nas quais produzia a "duplicação fotográfica" de sua vontade no cérebro de suas pacientes. Foram conduzidas experiências nas quais a pessoa hipnotizada cometia "crimes simulados" - sem saber que eram simulados.

Apesar do sucesso espetacular, e do imenso poder pessoal de Charcot na sociedade e com suas histéricas (verdadeiras Charquettes, diríamos hoje ...), e da disposição ilimitada dessas mulheres em colaborar com ele no que quer que ele almejasse provar, a escola de Paris nunca admitiu que a hipnose pudesse forçar alguém a praticar comandos repugnantes à sua natureza intima. Não obstante, não estava afastada a possibilidade de indução à participação passiva em crimes como o estupro, da qual a hipnotizada fosse a vítima. De fato, acreditava-se que as mulheres nem sequer deveriam viajar sozinhas nem olhar nos olhos de estranhos, pois o contato prolongado com o olhar de um macho predador bastaria para desencaminhá-las ${ }^{(3)} \ldots$

(3) HARRIS, Ruth. "Assassinato e loucura: medicina, leis e sociedade no fin del siècle". Rio de Janeiro: Ed. Rocco, 1993, p. 205. 


\section{A ESCOLA CRIMINOLÓGICA POSITIVA}

Lombroso e Ferri fizeram muitas cabeças por aqui, e continuam fazendo. O criminoso nato é um fantasma que assombra não só as nossas faculdades de direito, mas as conversas de botequim, as páginas policiais e os repórteres sensacionalistas, sem contar os políticos de extrema direita. Os positivistas, acuados pelas críticas ao exagerado da descrição, defenderam-se afirmando que esses caracteres [do criminoso nato] não estão todos presentes ao mesmo tempo em qualquer criminoso, mas podem aparecer em maior ou menor proporção em cada caso. Na verdade, eles aparecem, em maior ou menor grau, em qualquer ser humano ...

Note-se que a escola positivista de direito penal trabalha com um conceito de criminoso como aquele indivíduo que comete crime. Mas não necessariamente uma pessoa que pratica um ato tido como típico e ilícito penal positivado em alguma legislação, mas alguém que realiza uma conduta enquadrável num "conceito natural de crime", que, para Garófalo(4), é a "violação dos sentimentos altruísticos fundamentais de piedade e probidade, na medida média em que se acham na humanidade, por meio de ações prejudiciais à coletividade". Assim, quando um positivista penal fala em crime, ele não está falando da mesma coisa que um juiz, um advogado ou um promotor hodiernos falariam ao pronunciar a mesma palavra.

$\mathrm{Na}$ verdade, adotados os pressupostos do determinismo (seja o determinismo social da escola francesa, seja o determinismo biologizante da escola italiana), não se poderia mais falar em direito de punir, mas em direito de prevenir. $O$ direito penal transformar-se-ia num grande direito sanitário, e seu fundamento lastrear-se-ia na periculosidade, e não na culpabilidade. Ou seja, ao julgar alguém, o crime que ele cometeu (ou que nem sequer cometeu ainda, já que, no limite, isso é irrelevante) passa a servir apenas como baliza, como referencial para um diagnóstico de personalidade criminosa, vale dizer, um prognóstico da periculosidade do cidadão perante seus concidadãos. O Direito Penal passa a ser a prevenção de crimes futuros e inevitáveis, a serem cometidos por esse sujeito irremediavelmente mau contra os demais sujeitos irremediavelmente bons, a quem compete proteger para zelar por uma evolução adequada da sociedade. É a aplicação estrita do determinismo social ao direito.

\section{O FIM DO DETERMINISMO NAS CIÊNCIAS CHAMADAS "EXATAS"}

Houve, num determinado momento histórico (séculos XVIII e XIX, e início do século $X X$ ), a certeza de que a ciência desvendaria todos os mistérios da natureza - que seria uma questão de tempo chegar-se à

(4) Apud SODRÉ, Moniz. "As três Escolas Penais: clássica, antropológica e crítica”, 4aㅡ ed., São Paulo: Freitas Bastos, 1955, p. 129. 
reunião de todos os dados, à construção da "teoria sobre tudo", vale dizer, à elaboração das equações matemáticas com as quais o Universo fora construído - qual um imenso relógio. Com essa equação, desvendaríamos o passado e o futuro, e todas as coisas teriam explicação. Essa pretensão foi muito bem representada pelo chamado "Demônio de Laplace"(5) - uma inteligência superior que, sendo capaz de conhecer a posição e a velocidade de todos os elementos do universo num dado momento, fosse capaz de explicar inteiramente o passado e mais, fosse capaz de prever completamente o futuro.

Essa confiança na ciência (ciência, aí, entendida como o conhecimento do Homem sobre a Natureza) levou à necessidade de legitimar o conhecimento como um todo pela aproximação do paradigma científico aos outros campos do conhecimento humano que também deveriam ser tidos como científicos. Daí o positivismo comtiano ter proposto a aplicação do método científico ao conhecimento social, criando as ciências sociais sobre as mesmas bases epistemológicas da biologia, da física e da matemática. Portanto, questões como o livre-arbítrio, a responsabilidade moral e a liberdade foram, subitamente, catapultadas para um céu bastardo de uma filosofia deslegitimada, sob o manto da "metafísica" - palavrinha mágica que significava, grosso modo, isso não é um conhecimento verificável. Portanto, não é um conhecimento válido.

Para surpresa de todos, no entanto, a Física e a Matemática começaram a destruir um determinismo que estava funcionando muito bem - do ponto de vista ideológico e político - nas ciências sociais. A matemática começou a desenvolver suas geometrias não-euclidianas, a teoria do caos e representações nas quais, a depender dos pressupostos aceitos pelo observador, dois e dois não necessariamente seriam quatro. Foram desenvolvidos cálculos que representavam realidades inimagináveis, como universos em que o caminho mais curto entre dois pontos não era uma reta, e onde dimensões adicionais, além da quarta e da quinta, eram matematicamente plausíveis, embora absolutamente inverificáveis na prática.

Interessa-nos mais de perto o chamado "princípio da incerteza de Heisenberg". Por esse princípio, nunca se pode conhecer simultaneamente a velocidade e a posição de uma partícula subatômica. Vale dizer, se calcularmos a posição de um elétron, não conseguiremos determinar sua velocidade. Se calcularmos sua velocidade, não saberemos com certeza onde ele está num dado momento. Estava decretada a sentença de morte do demônio de Laplace.

É claro, portanto, que quando se fala em "determinismo", hoje, no mundo das ciências naturais, refere-se a alguma coisa muito diferente do determinismo de que se tratava nos séculos XVIII e XIX, bem como no início do século $X X$. Esse neodeterminismo é tão peculiar que o mesmo

(5) LAPLACE, Simon Pierre (1749-1827), astrônomo e matemático francês, autor de obras famosas como "Traité de Mécanique Celeste", "Exposition du Système du Monde" e "Theorie Analytique des Probabilités". 
Hawking chegou a afirmar : "não podemos nem sequer supor que a partícula possua uma velocidade e uma posição conhecidas por Deus mas ocultas para nós. Tais teorias de 'variáveis ocultas' prevêem resultados que destoam da observação. Mesmo Deus está limitado pelo princípio da incerteza e não pode conhecer a posição e a velocidade; ele só pode conhecer a função de onda"(6).

É hora, pois, de arrancar o determinismo social do direito penal.

\section{A REFORMA PSIQUIÁTRICA}

No processo dialético de convivência com a loucura, a própria ciência foi se dando conta da insuficiência da abordagem tradicional, vale dizer: a entrega do louco ao ambiente manicomial apenas o cronifica. O que se viu e se vê, na prática, é o agravamento da condição psicótica e a perda da possibilidade de retorno social ao louco que penetra nesse sistema.

Experiências ocorridas ao redor do mundo foram prenunciando uma abordagem menos formal e mais interdisciplinar à questão da loucura. Experiências como a de comunidades terapêuticas, na Inglaterra, e a psiquiatria preventivo-comunitária, nos Estados Unidos, têm essa direção. Duas experiências são muito citadas como fundamentadoras da experiência de reforma psiquiátrica vivida no Brasil: a antipsiquiatria e a psiquiatria democrática formulada com base nas experiências de Franco Basaglia.

Diríamos, para ser sintético, e abordar aquilo que nos interessa, que a reforma psiquiátrica - como hoje é vista no âmbito do direito sanitário, implica ter a noção de cidadania como idéia central na abordagem do paciente em busca da saúde mental, e passa por alguns parâmetros, que poderiam ser enumerados assim: a) abordagem interdisciplinar da saúde mental, sem prevalência de um profissional sobre o outro; b) negativa do caráter terapêutico do internamento; c) respeito pleno da especificidade do paciente, e da natureza plenamente humana da sua psicose; d) discussão do conceito de "cura", não mais como "devolução" ao paciente de uma "sanidade perdida", mas como trabalho permanente de construção de um "sujeito" (eu) ali onde parece existir apenas um "objeto" de intervenção terapêutica (isso); e) a denúncia das estruturas tradicionais como estruturas de repressão e exclusão; f) a não-neutralidade da ciência; g) o reconhecimento da inter-relação estreita entre as estruturas psiquiátricas tradicionais e o aparato jurídico-policial.

\section{LOUCURA E DIREITO. QUESTÕES GERAIS}

Salta aos olhos que logo no primeiro artigo a Constituição Federal eleja a dignidade da pessoa humana como fundamento da República Fe-

(6) Id. ibid., p. 107. 
derativa do Brasil. Esse conceito - dignidade da pessoa humana - é profundamente caro às sociedades cristãs ocidentais contemporâneas. Lastreada na concepção kantiana da pessoa como fim, e nunca como meio, a cultura ocidental resgatou o conceito, notadamente após a Segunda Guerra e seus horrores, diante da constatação de que o formalismo do positivismo jurídico seria insuficiente para impedi-los.

Mesmo as noções tradicionais de dignidade da pessoa humana e de cidadania (garantida na sua integridade pelo art. 5 da Constituição Federal), entretanto, revelam-se problemáticas quando se tenta aplicá-las àqueles tidos como loucos, como psicóticos, no plano da visão tradicional sobre a loucura. Ao tratar da questão da dignidade, os autores sempre buscam sua raiz na autonomia, na sua capacidade de raciocinar e determinar-se de acordo com seu entendimento, sua livre vontade, sem ser compelido por forças externas. Nada se discute sobre a pessoa humana que tem sua capacidade de entendimento ou de determinação tolhida por forças internas ${ }^{(7)}$.

A noção de autonomia também é amplamente discutida entre os autores que tratam da reforma psiquiátrica. Para eles, a questão da autonomia é muito mais quantitativa do que qualitativa - a antítese autonomia-dependência marca a própria vida humana. Somos tão mais autônomos na medida em que conseguimos ampliar o número de coisas/relações de que somos dependentes. Somos tão menos autônomos quanto menor o número dessas coisas/relações de que dependemos. Esse é, inclusive, o sentido moderno do tratamento das disfunções mentais.

Nesse sentido, o conceito constitucional de respeito ao pluralismo político (art. 1ㅇ, V) deve ser aproveitado para garantir-se que o respeito à cidadania e a dignidade aconteça essencialmente no plano do respeito aos múltiplos modos pelos quais a razão e a desrazão se manifesta. Devese ter consciência de que a cidadania não deve ser uma camisa-de-força jurídica, um modelo rígido no qual se tentará enfiar violentamente aquele que nela não cabe. Deve, isso sim, ser um conceito fluido, capaz de ajustar-se à infinita multiplicidade do jeito humano de ser. Isso implica um alargamento do próprio conceito de pluralismo político, para entendê-lo como a necessidade de respeito à pluralidade humana.

Assim, será preciso construir uma noção de cidadania que não seja externa ao próprio psicótico, que não o exclua a priori por estar além ou

(7) FONTES JR., em trabalho inédito, trata da dignidade da pessoa humana de forma magistral, aponta as limitações práticas dessa noção, dizendo: "A doutrina não tem o menor receio de confessar que o termo the escapa e que as formulações gerais são insatisfatórias, que a dignidade é uma noção com corpo semântico relativamente impreciso, alertando para o fato de que o problema é muito mais grave do que aparenta; em verdade, a dignidade da pessoa vem sendo invocada para defenderem-se soluções radicalmente contrárias sobre questões fundamentais como a admissibilidade do aborto e da eutanásia". (FONTES JR., João Bosco Araújo. "Liberdades fundamentais e segurança pública: do direito à imagem ao direito à intimidade: a garantia constitucional do efetivo estado de inocência". Lisboa: Faculdade de Direito da Universidade de Lisboa, 2002, p. 23). 
aquém da sua própria capacidade enquanto ser humano pleno e diferente, como de resto somos todos. Uma noção de cidadania que não parta de "desempenhos eleitos pelos profissionais como desejáveis segundo a sua própria concepção de autonomia, e não aquilo que o sujeito vivencia como a maneira como a doença se articula em sua vida"(8).

Não se pode negar, portanto, que pensar a questão da insanidade, na sua interface com a cidadania, é, de certa forma, repensar a própria questão dos conceitos de cidadania, dignidade da pessoa humana e pluralismo político. A incapacidade do louco de "cumprir e respeitar o contrato social" tem-no transformado simplesmente em alguém mais além da própria proteção que esse contrato estabelece. Evidencia-se o poder limitado de pressupostos filosóficos que lastreiem a dignidade na razão.

Essa limitação evidencia-se especialmente no tratamento constitucional ao criminoso. "Ninguém será privado da liberdade ou de seus bens sem o devido processo legal", diz a Constituição, no seu art. 5, inciso LIV. Mas, garantir o devido processo legal a quem o próprio direito reconhece não entender seus termos não passa de uma ficção. A mesma Constituição estabelece, no mesmo artigo (inciso LVII), que ninguém será considerado culpado até o trânsito em julgado da sentença penal condenatória. Ora, o pressuposto para que alguém seja apenado é que ele seja considerado culpado por sentença penal condenatória. A pena não deve, ademais, passar da pessoa do condenado (inciso XLV do mesmo artigo), o que estabelece uma dupla garantia: A responsabilidade estritamente subjetiva (lastreada na culpa em sentido lato, quer dizer, no dolo e na culpa em sentido estrito) e a pessoalidade da sanção.

Estabelecer, portanto, a constitucionalidade de um direito penal dirigido ao inimputável, e baseado na periculosidade social (juízo para o futuro) e não na culpabilidade (juizo para o passado) é muito complicado, do ponto de vista da afinação com a Constituição vigente. Submetê-lo a processo penal para aplicar-Ihe uma medida de segurança é, em igual medida, complicadíssimo. Onde encontrar a culpa de quem é legalmente irresponsável? Como garantir o devido processo penal a quem não pode sequer entender seus termos? Como garantir a pessoalidade (a pena não deve passar da pessoa do condenado) se o louco deve ser absolvido e depois apenado?

Para que fosse constitucional julgar alguém após reconhecê-lo mentalmente enfermo a ponto de não ter noção do que faz, ou de não poder conduzir-se de acordo com essa noção, sob o fundamento da periculosidade social, seria preciso que a Constituição determinasse que "ninguém será considerado culpado ou perigoso socialmente até o trânsito em julgado de sentença penal condenatória ou de sentença penal absolutória que reconheça tal periculosidade, nos termos da lei".

(8) TENÓRIO, Fernando. "A psicanálise e a clínica da reforma psiquiátrica". Rio de Janeiro: Marca D'água Livraria e Ed., 2001, p. 65. 
É claro que um texto assim soaria profano aos ouvidos de qualquer constitucionalista, pelo grau de insegurança jurídica que ele geraria. Mas o texto vem sendo aplicado dessa exata forma para aqueles tidos como "loucos perigosos" pela Justiça, sem que nenhum constitucionalista jamais se desse conta, ou sem que nenhum penalista jamais questionasse os fundamentos constitucionais de uma "absolvição imprópria" - absolvição com imposição de medida de segurança - no âmbito do direito penal.

\section{PRINCÍPIOS DO DIREITO SANITÁRIO}

É preciso falar um pouco dos princípios atinentes ao direito sanitário, incluidos os princípios atinentes ao Sistema Único de Saúde: é ali que se vê a contradição mais evidente entre a medida de segurança penal e o discurso ideológico que a lastreia considerando-a como se ela tivesse uma natureza sanitária: os estabelecimentos onde se cumprem as medidas de segurança são considerados como estabelecimentos hospitalares (art. 99 do Código Penal). Mas, embora sejam considerados como estabelecimentos hospitalares públicos, não integram o Sistema Único de Saúde, mas o sistema penitenciário. Isso significa que não são regidos pelos princípios do SUS (Constituição, art. 196 e seguintes, Leis ns. 8.080 e 8.142/90), mas pelos princípios da execução penal (Lei n. 7.210/84).

Não é fácil entender como um penalista e um constitucionalista poderiam harmonizar essa contradição principiológica. Afinal, hospital público e instituição penitenciária são instituições regidas por princípios absurdamente diversos e incongruentes entre si. Portanto, não há como defender que a medida de segurança tem natureza sanitária e não punitiva sem evidenciar a contradição de um "hospital" submetido ao sistema penitenciário, e não ao Sistema Único de Saúde.

É preciso, nesse passo, fazer uma digressão sobre os princípios do SUS e da própria saúde pública no Brasil, que regem a legislação de reforma psiquiátrica. Como foi dito, para entender o sistema sanitário brasileiro, duas leis são fundamentais: as Leis ns. 8.080/90 e 8.142/90. Essas leis estabelecem princípios de direito sanitário, afinadíssimos com a Constituição Federal, que poderiam ser enumerados, em apertadíssima síntese, assim: a saúde é um direito do cidadão, oponivel ao Estado. Os serviços de saúde devem ter oferta universal e eqüitativa, considerando a situação concreta de grupos e indivíduos. A atenção à saúde será sempre integral e resolutiva, vale dizer, eficiente. As ações de saúde devem ser intersetoriais, e humanizado o atendimento à comunidade - que, aliás, deve participar, democraticamente, do conhecimento do processo saúde/doença e do planejamento dos serviços, decidindo e controlando o processo.

A estruturação do SUS obedece, também, a uma série de diretrizes, igualmente traçadas pela Constituição e pelas Leis ns. 8.080/90 e 8.142/90. 
Citemo-las: descentralização, com representação de todos os níveis do Estado e do Governo, hierarquização, com estabelecimento de níveis de complexidade na distribuição dos serviços e ações, regionalização, para atingir racionalmente toda a população, financiamento público e controle social.

Lastreada nesses princípios, encontramos a Lei $n$. 10.216/2001, que trata exatamente da proteção e dos direitos das pessoas portadoras de transtornos mentais e redireciona o modelo assistencial em saúde mental. Notese, de logo, que a lei não excepciona do seu texto os portadores de transtornos que tenham cometido crime, de modo que também esses são atingidos por ela. Não há motivo para excluí-los da aplicação desse diploma, sem promover uma discriminação que não tem o menor suporte na Constituição Federal. Ao contrário, o seu art. $1^{\circ}$ determina que os direitos ali assegurados aos portadores de transtornos mentais devem ser garantidos "sem qualquer forma de discriminação", incluída aí a discriminação pelo fato da "passagem ao ato", vale dizer, do cometimento de fato previsto na lei como crime.

Já está evidente, no entanto, que esses princípios e diretrizes têm plena aplicação no tratamento dos portadores de transtornos mentais, tenham eles cometido fato capitulado como crime ou não. As questões de conflito entre tais princípios e diretrizes com os princípios do direito penal e da execução penal serão tratadas em seguida.

\section{A LEGISLAÇÃO DE REFORMA PSIQUIÁTRICA E O SISTEMA PENAL}

Os princípios do SUS, suas diretrizes e os princípios específicos previstos na lei de reforma psiquiátrica aplicam-se, integral e imediatamente, aos manicômios judiciários onde estão internados os loucos que cometeram fatos descritos na lei penal, bem como à relação entre o mundo jurídico e eles próprios. Esse assunto foi tratado, numa primeira abordagem, no Seminário Nacional para a Reorientação dos Hospitais de Custódia e Tratamento Psiquiátrico, promoção conjunta do Departamento Penitenciário Nacional do Ministério da Justiça e do Ministério da Saúde, através da Secretaria de Assistência à Saúde, área técnica de Saúde Mental, ocorrido em setembro de 2002. Uma das conclusões ali adotada e transcrita nos anais (publicados no tomo "Legislação em Saúde Mental", do Ministério da Saúde, texto integral disponível na Internet, no endereço www.ms.gov.br), é a de que "nos estados onde existam manicômios judiciários, as condições minimas devem se adequar às normas do SUS, com as mesmas regras para os hospitais psiquiátricos públicos ou credenciados aos SUS, direcionadas no sentido da humanização, desospitalização e desinstitucionalização, evoluindo para o regime aberto" (Grupo de trabalho 03).

A outra questão essencial, que decorre da promulgação dessa lei, é a derrogação da lei de execuções penais, no que respeita às medidas de segurança, já que, como foi dito, seu teor aplica-se aos pacientes que 
cometeram ou não fato descrito como crime na lei penal. Assim, normas como a do seu art. 5ㅇ, que determina que o paciente há longo tempo hospitalizado ou para o qual se caracterize situação de grave dependência institucional, decorrente de seu quadro clínico ou de ausência de suporte social, será objeto de política específica de alta planejada e reabilitação psicossocial assistida, sob responsabilidade da autoridade sanitária competente e supervisão de instância a ser definida pelo Poder Executivo, assegurada a continuidade do tratamento, quando necessário, deve ser de pronto aplicada para os atuais internos de manicômios judiciais.

Há, portanto, conflito entre essa lei - posterior - e a lei de execuções penais - anterior. Citem-se, como exemplos, o art. 97 , $\S \S 1^{\circ}$ e $2^{\circ}$, com seus prazos mínimos obrigatórios para a realização e repetição de regimes (com seus correlatos arts. 175 a 179 da lei de execuções penais) - incompatíveis com o princípio da utilidade terapêutica do internamento, previsto no art. $4^{\stackrel{0}{ }}$, $\S 1 \stackrel{\circ}{ }$, da lei de reforma psiquiátrica, ou com o princípio da desinternação progressiva dos pacientes cronificados (art. $5^{\circ}$ da lei de reforma psiquiátrica). Além disso, os direitos mínimos garantidos na lei de execução penal àquele que cumpre medida de segurança (art. 99, parágrafo único, da lei de execuções penais) confrontam-se com aqueles muito mais amplos assegurados no art. $2^{\circ}$ da lei de reforma psiquiátrica, e a classificação do hospital de custódia e tratamento psiquiátrico como estabelecimento penal (Título IV, Capítulo VI da Lei de Execuções Penais) está em desacordo com os princípios do SUS, constitucionais e infraconstitucionais, como já foi visto acima.

São logicamente incompatíveis dispositivos do sistema penal que determinam a presunção de periculosidade do louco e o seu tratamento em função do tipo de delito que cometeu (se punido com detenção ou reclusão), baseado em prazos fixos e rígidos, com as normas sanitárias que determinam que o tratamento visará como finalidade permanente a reinserção social do paciente em seu meio, e que o internamento só será indicado quando os recursos extra-hospitalares mostrarem-se insuficientes (art. $4^{\circ}$ e parágrafos da lei de reforma psiquiátrica).

De idêntica importância, e igualmente de aplicação imediata, são os artigos que estabelecem que a internação psiquiátrica somente será realizada mediante laudo médico circunstanciado que caracterize os seus motivos (art. 6으 da lei de reforma psiquiátrica). Parece que teremos que repensar o princípio, atualmente aceito de forma pacífica, de que as medidas de segurança são estabelecidas com base no apenamento do respectivo tipo penal (reclusão corresponde a internamento, detenção corresponde a tratamento ambulatorial). Pela nova sistemática, internamento ou tratamento ambulatorial decorrem de recomendação da equipe interdisciplinar que lida com o paciente, e não de determinação judicial ou legal.

\section{UMA PEQUENA DISCUSSÃO SOBRE MEDIDA DE SEGURANÇA}

A medida de segurança parece ser o ponto de equilíbrio entre as escolas penais clássica e positiva, uma conciliação pragmática que não conse- 
gue lançar raizes profundas em nenhuma das duas escolas. De fato, dentro dos conceitos filosóficos da escola clássica, um homem nunca poderia ser julgado por um crime que ele não quis ou não tinha condição de compreender, nem ser submetido a qualquer tipo de resposta penal em razão de fatos sobre os quais ele não teve responsabilidade, do ponto de vista subjetivo. Todo o fundamento do direito de punir, para os defensores dessa escola, estava arraigado na questão da responsabilidade subjetiva, sendo o livrearbítrio o fundamento de tal responsabilidade. A pena seria a retribuição para aquele que, livremente, optou por descumprir a lei. Aquele que não tem liberdade para fazer essa opção está fora do direito penal, não se submetendo, portanto, nem à sua jurisdição, nem às sanções por ele prescritas. Para os cultores da escola positiva de direito penal, estamos todos submetidos às forças determinantes da natureza, portanto nenhum de nós goza de verdadeira - senão aparente - liberdade. Assim, o fundamento do direito de punir está na defesa social contra aquele que, por sua peculiar condição evolutiva, genética ou social, ameaça ao conjunto dos integrantes da sociedade que não estão submetidos às mesmas forças deterministas criminógenas. Haveria, portanto, essencialmente, identidade entre pena e medida de segurança - toda pena é, no fundo, uma medida de segurança ${ }^{(9)}$.

Fundou-se o binômio pena-culpabilidade, medida de segurança-periculosidade $^{(10)}$, no qual a pena sempre leva em conta a periculosidade ${ }^{(11)}$, mas a medida de segurança não leva em consideração, senão de forma acidental, a culpabilidade.

Cabe discutir um pouco o conceito de medida de segurança. Segundo Ferrari, "a medida de segurança constitui uma providência do poder político que impede que determinada pessoa, ao cometer um ilícito-típico e se revelar perigosa, venha a reiterar na infração, necessitando de tratamento adequado para sua reintegração social" (12). Para Damásio de Jesus, "as penas e as medidas de segurança constituem as duas formas de sanção penal. Enquanto a pena é retributivo-preventiva, tendendo atualmente a readaptar socialmente o delinqüente, a medida de segurança possui natureza essencialmente preventiva, no sentido de evitar que um sujeito que praticou um crime e se mostra perigoso venha a cometer novas infrações penais"(13).

(9) Para uma comparação entre as escolas penais, ver SODRÉ, Moniz, op. cit. Frise-se que não se trata de uma comparação imparcial, porque o autor é um positivista penal ardoroso.

(10) BITENCOURT, Cezar Roberto. "Manual de direito penal: parte geral", 4ª ed., São Paulo: Ed. Revista dos Tribunais, 1997, p. 665.

(11) Veja-se o quanto a periculosidade entra na fixação da pena dos imputáveis, examinandose, entre outros, os dispositivos do art. 44, III e art. 83, parágrafo único, do Código Penal.

(12) FERRARI, Eduardo Reale. "Medidas de segurança e direito penal no Estado democrático de direito". São Paulo: Ed. Revista dos Tribunais, 2001, p. 15.

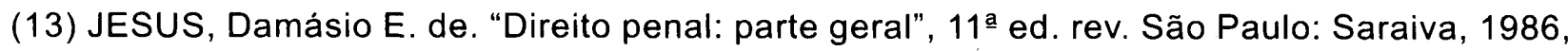
v. 1, p. 473. O autor prossegue, ressaltando: "As medidas de segurança diferem das penas nos seguintes pontos: a) as penas têm natureza retributivo-preventiva. As medidas de segurança são preventivas; b) as penas são proporcionais à gravidade da infração; a proporcionalidade das medidas de segurança fundamenta-se na periculosidade do sujeito; c) as penas ligam-se 
E quem é o perigoso? Para a doutrina, periculosidade é a "potência, a capacidade, a aptidão ou a idoneidade que um homem tem para converterse em causa de ações danosas ${ }^{(14) "}$. Ora, como em tese qualquer pessoa viva tem a potência, a capacidade e a aptidão ou idoneidade para converter-se em causa de ações danosas, não faltaram autores para apontar a imprecisão de tal conceito ${ }^{(15)}$, tendo o direito penal brasileiro adotado o princípio da presunção de periculosidade para o inimputável que praticar fato típico e antijurídico. Mas mesmo essa presunção é por demais problemática - como avaliar os elementos subjetivos do tipo, ou mesmo da antijuridicidade, quanto a alguém que é considerado legalmente inimputável?

Estão estabelecidos, portanto, os principais conflitos em termos de definição doutrinária das medidas de segurança: Alguns autores, como Damásio, consideram-na como uma sanção penal. Outros, como Ferrari, vêem nela apenas uma "medida política" aplicável para possibilitar um "tratamento adequado" para a reinserção social do sujeito que, ao cometer fato típico, demonstre presumida periculosidade social.

\section{MEDIDA DE SEGURANCCA E REFORMA PSIQUIÁTRICA - A IMPOSSÍVEL CONCILIAÇÃO}

Podemos, pois, a essa altura, introduzir a questão que está sendo gestada neste trabalho: a medida de segurança é sanção penal ou tratamento terapêutico? Não há uma resposta clara a essa pergunta, nem no plano filosófico, nem no plano doutrinário, nem no plano legal, a essa altura do desenvolvimento do nosso direito. Isso não nos tira a responsabilidade de raciocinar sobre o tema.

Dizer que a medida de segurança é um tratamento de natureza terapêutica, que visa ao restabelecimento e a reintegração do louco, garantindo-se apenas circunstancialmente a segurança da sociedade contra sua periculosidade seria, por outro lado, afirmar que, em matéria de medida de segurança, estamos tratando de direito sanitário, e não de direito penal stricto sensu. Essa é, portanto, uma terapia sui generis: aplicada e dosada pelo juiz, numa instituição que apesar de ter "características hospitalares"

ao sujeito pelo juizo de culpabilidade (reprovação social); as medidas de segurança, pelo juízo de periculosidade; d) as penas são fixas; as medidas de segurança são indeterminadas, cessando com o desaparecimento da periculosidade do sujeito; e) as penas são aplicáveis aos inimputáveis e semi-responsáveis; as medidas de segurança não podem ser aplicadas aos absolutamente imputáveis".

(14) Soler, apud JESUS, Damásio E. de op. cit., p. 473.

(15) "Periculosidade é um juizo eminentemente subjetivo que, por infelicidade, ficou colocado na lei como se fosse cânone objetivo inflexível. Ou seja, se o autor do delito for um inimputável ele automaticamente é considerado perigoso e receberá fatalmente uma medida de segurança, precisando ou não do tratamento e da contenção" (FÜHRER, Maximiliano Roberto Ernesto, op. cit., p. 142). 
é uma instituição do sistema carcerário. Trata-se, portanto, de uma medida terapêutica que o próprio Sistema Único de Saúde - e a própria ciência, como foi visto nos capítulos anteriores - está repensando, e está caminhando para a conclusão de que ela é, no mais das vezes, descabida e inconveniente. Mais - da forma com que está prevista no nosso direito atualmente, ela seria um tratamento cuja alta não se dá em razão pura e simples da recuperação do paciente, mas pela sua submissão à "perícia de cessação de periculosidade" periódica, submetida ao juiz, que passaria, sem ser médico, a ter o "poder clínico" de considerar o "paciente" curado, mesmo quando a própria ciência discute se é possível falar em "cura da loucura". Seria, além do mais, um tratamento imposto no âmbito de um processo penal, por um juiz com competência penal, mas sob um discurso sanitarista. Há, portanto, um completo descompasso entre aquilo que se considera como medida de segurança no direito penal, e aquilo que hoje se considera como medida terapêutica para pacientes com transtornos mentais, na ciência e no próprio direito sanitário, como foi visto.

No atual estágio do direito brasileiro, não se pode defender que internar alguém coativamente (ou mesmo submetê-lo a um tratamento ambulatorial coativo), por ordem judicial de um juiz criminal, com base numa presunção de periculosidade (decorrente da prática de um ato criminal por alguém que foi reconhecido pelo direito como portador de transtorno mental incapacitante das faculdades cognitivas ou volitivas) seja considerado cientificamente como medida terapêutica. Tampouco se pode admitir que, no âmbito do direito sanitário, se possa reconhecer a validade desse procedimento como clinicamente eficaz. A reforma psiquiátrica - e sua projeção no mundo jurídico - descaracterizaram absolutamente a abordagem coativa, manicomial, unidisciplinar, repressora, como uma abordagem clinicamente eficaz. Portanto, o jurista que estiver empregando a medida de segurança lastreado na convicção de que está utilizando uma medida terapêutica de cunho sanitário está se enganando. Em tempos de movimento antimanicomial, só um louco defenderia a internação compulsória como terapia bastante e suficiente para a reintegração do inimputável. Não há como ocultar, portanto, que essa medida não se dá em benefício do portador de transtornos mentais, mas que se dá tãosomente em favor da sociedade que se considera agredida e ameaçada pelo inimputável que cometeu um fato descrito pela lei como típico.

Essa argumentação, ademais, pode ser derrubada com uma observação muito simples: a lei de execuções penais coloca os hospitais de custódia e tratamento psiquiátrico dentro do seu Título IV, que trata exatamente dos estabelecimentos penais. Vale dizer: juridicamente os HCTP's são estabelecimentos penais, e não estabelecimentos de saúde. São espaços cuja regulamentação se dá por remissão(16) ao art. 88 da lei de execuções penais, ou seja, onde "o condenado será alojado em cela indi-

(16) A remissão está no art. 99, parágrafo único, da lei de execuções penais. 
vidual, que conterá dormitório, aparelho sanitário e lavatório". Um estabelecimento penal é um lugar para onde se vai primordialmente cumprir pena, e somente num plano secundário obter terapia.

Por outro lado, dizer claramente que a medida de segurança é uma sanção penal teria um poder de expor as contradições de um sistema penal construído com base em pressupostos filosóficos e constitucionais liberais e clássicos, mas que admite a responsabilização penal objetiva daquele que, por ser louco, reconhecidamente não pode conhecer o caráter ilícito do fato, ou comportar-se na conformidade desse entendimento.

Pela inércia que acomete a prática judicial, aprendemos e ensinamos, na formação jurídica, a "curiosidade" de que o nosso direito conhece uma "sentença absolutória atípica", que determina que não há como considerar o réu culpado (por não reconhecer-lhe sanidade) absolvendo-o, mas aplicando-Ihe uma sanção penal. Qual o fundamento disso? O único fundamento seria imaginar que a medida de segurança não é uma sanção penal, mas coisa diversa. Caso contrário, esbarrar-se-ia numa inconstitucionalidade. Mas que coisa diversa seria essa, não se sabe.

Todas essas questões mostram como é complicado considerar a medida de segurança como uma sanção de natureza penal, no atual estágio do ordenamento. Demonstram, também, como é complicado considerá-la simplesmente como uma medida sanitária. A rigor, o reconhecimento de que alguém, em razão de transtornos mentais, não é responsável pelos seus atos deveria implicar a extinção imediata da jurisdição penal sobre ele. Caso contrário, alguém que não é considerado culpado, e que é absolvido, é submetido a uma sanção penal, por um juiz penal, com base apenas numa conveniência social. Com o avanço filosófico, clínico e jurídico representado pela reforma psiquiátrica, a própria natureza da medida de segurança deve ser repensada. Urge reconstruir o próprio conceito de responsabilidade penal, de responsabilidade jurídica do louco, para torná-lo mais consentâneo com a visão contemporânea sobre a loucura.

A devolução da voz e da cidadania ao sujeito com transtornos mentais vai implicar uma devolução de responsabilidade. Para construir essa responsabilização, será necessária uma boa dose de pluralismo e de abertura a outros saberes, mas acima de tudo um profundo questionamento dos conceitos jurídicos de responsabilidade civil e penal, e de um repensar de estruturas arcaicas, como a medida de segurança, incoerentes com o ordenamento atual, mas aplicadas por inércia jurídica. Não se defende a irresponsabilidade, mas a construção de uma responsabilidade plúrima, sábia e consentânea com o modo peculiar de ser, de agir e de pensar desses cidadãos, e que vise realmente a sua reintegração, quando ele passar ao ato, vale dizer, quando agir de uma forma que venha a prejudicálo ou a prejudicar injustamente a um terceiro. Somente um diálogo multilateral, interdisciplinar e democrático - que inclua, ademais a participação desses cidadãos com necessidades especiais - pode nos apontar um caminho para a construção de uma cidadania que se ajuste ao modo especial de ser. O caminho é longo. 
Repensar a abordagem jurídica à questão da loucura, em matéria criminal, implica repensar os próprios alicerces filosóficos do direito penal: os fundamentos e a função social do direito de punir. A potencialidade de prejudicar a outrem, e em particular de cometer crime, é da essência da pessoa humana, "louca" ou "sã". Perigosos somos todos, em tese - embora não se possa negar que haja uma possibilidade de prever que o ser humano, submetido a determinadas condições, tem uma maior probabilidade de cometer crimes. Essa é uma ilação probabilística, no entanto. Não pode servir de base filosófica para a construção de todo um sistema repressivo independentemente da noção de culpa como fundamento da responsabilidade penal.

Teremos, portanto, de construir um sistema de responsabilização do louco que "passe ao ato" (vale dizer, que comete crimes) - que leve em conta a necessária integridade do sistema jurídico. No momento há apenas o vácuo, no qual, por inércia, aplicamos o sistema das medidas de segurança sem pensar muito em sua coerência. Propomos a criação de um sistema de responsabilização coerente com os avanços da reforma psiquiátrica. Talvez seja necessário escapar dos limites do direito penal, quiçá promover um amplo debate desse próprio campo do direito, reformulando-o.

\section{REFERÊNCIAS BIBLIOGRÁFICAS}

BITENCOURT, Cezar Roberto. "Manual de direito penal: parte geral". 4" ed., São Paulo: Ed. Revista dos Tribunais, 1997.

CARRARA, Sérgio. "Crime e loucura: o aparecimento do manicômio judiciário na passagem do século". São Paulo: Ed. Edusp, 1998.

FERRARI, Eduardo Reale. "Medidas de segurança e direito penal no Estado democrático de direito". São Paulo: Ed. Revista dos Tribunais, 2001.

FONTES JR., João Bosco Araújo. "Liberdades fundamentais e segurança pública: do direito à imagem ao direito à intimidade: a garantia constitucional do efetivo estado de inocência". Lisboa: Faculdade de Direito da Universidade de Lisboa, 2002.

FOUCAULT, Michel. "História da loucura na idade clássica". São Paulo: Perspectiva, 2002.

"Vigiar e punir". 19a ed., Petrópolis (RJ): Ed. Vozes, 1999.

FÜHRER, Maximiliano Roberto Ernesto. "Tratado da inimputabilidade no direito penal". São Paulo: Malheiros Ed., 2000.

HARRIS, Ruth. "Assassinato e loucura: medicina, leis e sociedade no fin del siècle". Rio de Janeiro: Ed. Rocco, 1993. 
HAWKING, Stephen. "O universo numa casca de noz". São Paulo: Ed. Mandarim, 2001.

JESUS, Damásio E. de. "Direito penal: parte geral", 11aㅡ ed., rev. São Paulo: Saraiva, 1986. v. 1.

va, 2000.

. "Código Penal anotado", 10ª ed. rev. e atual., São Paulo: Sarai-

RIBEIRO, Paulo Rennes Marçal. "Saúde mental no Brasil". São Paulo: Arte e Ciência, 1999.

SODRÉ, Moniz. "As três Escolas Penais: clássica, antropológica e crítica", 4aㅡ ed., São Paulo: Freitas Bastos, 1955.

TENÓRIO, Fernando. "A psicanálise e a clínica da reforma psiquiátrica". Rio de Janeiro: Marca D’água Livraria e Ed., 2001. 